\title{
The Role of Interferon in Persistent Infection with Foot-and-Mouth Disease Virus
}

\author{
BY L. PHILIPSON AND Z. DINTER \\ Institute of Virology, University of Uppsala, Uppsala, \\ and the State Veterinary Institute, Stockholm, Sweden
}

(Received 5 February 1963)

\begin{abstract}
SUMMARY
Calf kidney cell cultures persistently infected with foot-and-mouth disease virus (FMDV) resist challenge with related and unrelated viruses. Attachment of challenge virus to persistently infected cells is not impaired. A challenge with viral ribonucleic acid (RNA) will not overcome the resistance of persistently infected cells. The initiation of persistence is correlated with the amount of interferon produced in the cells. It is concluded that interferon plays a major role in initiation and maintenance of the carrier state of the cells.
\end{abstract}

\section{INTRODUCTION}

Interferon, a soluble product of virus-infected cells capable of interfering with replication of a wide range of viruses (Isaacs, 1961), plays a role in the initiation and maintenance of chronic virus infections in vitro (Ho \& Enders, 1959; Henle, Henle, Deinhardt \& Bergs, 1959; Chany, 1961; Glasgow \& Habel, 1962). Baron \& Isaacs (1961) recently reviewed the evidence, which suggests that interferon may be important in natural recovery from viral infections. Foot-and-mouth disease virus (FMDV), which induces marked degeneration in calf kidney cells, gives rise to a persistent infection when the early cycles of multiplication are suppressed by the presence of viral antibodies (Dinter, Philipson \& Wesslén, 1959). The antibodies can subsequently be removed and most cells will remain intact. The cultures produce active virus for at least 20 days. Prolonged treatment with viral antibodies cures the cultures from the carrier state (Dinter et al. 1959). An interferon-like inhibitor from calf kidney cells infected with FMDV was recently described (Dinter \& Philipson, 1962). This formed the basis for investigating the role of interferon in the initiation and maintenance of the carrier state in cells persistently infected with FMDV. The present study demonstrates the resistance of such cells to related and unrelated viruses and the role of interferon in this process.

\section{METHODS}

Viruses. The Lindholm $\mathrm{O}_{2}$-strain of FMDV (FMDV $\mathrm{O}_{2}$ ), the Brussels $\mathrm{A}_{5}$ strain of FMDV (FMDV $A_{5}$ ), a strain of parainfluenza virus type 3 (PI-3), a virulent strain of poliovirus type 1 (E 206) and the $\mathrm{Z}$ strain of pseudo-rabies virus were used. Poliovirus stocks were prepared in monkey kidney cultures, the others in calf kidney cultures. FMDV and poliovirus were stored at $+4^{\circ}$ and the other viruses at $-60^{\circ}$.

Cell cultures and virus assay. The preparation of cell cultures, the plaque technique, 
and the methods for virus assay have been described previously (Dinter \& Philipson, 1962). Virus infectivity is expressed as the logarithm of the $50 \%$ endpoint (log TCD 50)/ml. when tube titrations were used or as plaque-forming units (p.f.u.)/ml. when plaque assay was performed. When two viruses were present in samples to be tested, one of them was neutralized by antiserum before assay. Hemagglutinating activity of PI-3 virus was expressed as the $\log _{2}$ of the reciprocal of the greatest dilution of the sample giving complete agglutination in tube tests.

Persistently infected cultures. Flask cultures of calf kidney were exposed to about $10^{4}$ TCD 50 of FMDV $\mathrm{O}_{2}$. After incubation for $90 \mathrm{~min}$. at $37^{\circ}, 50 \mathrm{ml}$. of Hanks's salt solution $+\mathbf{0} \cdot 5 \%(\mathrm{w} / \mathrm{v})$ lactalbumin hydrolysate and antibiotics $(\mathrm{H}+\mathrm{Lah})+$ $\mathbf{0 . 5} \%(\mathrm{v} / \mathrm{v})$ immune serum were added. After incubation for about $42 \mathrm{hr}$. at $37^{\circ}$ the medium was changed to $\mathrm{H}+\mathrm{Lah}+2 \%(\mathrm{v} / \mathrm{v})$ normal calf serum. After a further $18 \mathrm{hr}$. at $37^{\circ}$ the cells were trypsinized and subcultured in tubes or Petri dishes. $\mathrm{H}+\mathrm{Lah}+2 \%(\mathrm{v} / \mathrm{v})$ normal calf serum was used as medium for these cultures. Control cultures from the same calf kidneys were treated the same way in each experiment except for virus inoculation and are designated normal cultures.

Cured cultures. Antiviral serum at a final concentration of $1 \%(\mathrm{v} / \mathrm{v})$ was added to the medium of persistently infected cells in Petri dishes. The cultures were then incubated for a period of 6 days and the medium containing antiserum was replaced by $\mathrm{H}+\mathrm{Lah}+2 \%(\mathrm{v} / \mathrm{v})$ normal calf serum. On each of the following 3 days the medium of these cultures was assayed for virus infectivity. If no virus was found the cultures were considered 'cured'.

Antiserum. FMDV antiserum was obtained from cattle and guinea pigs hyperimmunized against the respective virus.

Production and assay of interferon. Interferon was produced in calf kidney cells and assayed as previously described (Dinter \& Philipson, 1962). Interferon titre was expressed as the reciprocal of the final dilution resisting a challenge of 100 TCD 50 of pseudo-rabies virus.

Extraction of viral $R N A$. Viruses were concentrated by aqueous polymer phase systems (Philipson, Albertsson \& Frick, 1960) and treated with phenol saturated with $0 \cdot 02 \mathrm{M}$-phosphate buffer $(\mathrm{pH} 7 \cdot 4)$ containing $10^{-4} \mathrm{M}$-ethylenediaminetetraacetate (EDTA) at $4^{\circ}$ according to Gierer \& Schramm (1956). The water phase was collected and shaken six times with ether, which was subsequently removed by nitrogen. This material was assayed for infectivity with and without treatment for $10 \mathrm{~min}$. at $37^{\circ}$ with ribonuclease (recrystallized three times, Worthington Inc., New Jersey, U.S.A.) at a final concentration of $10 \mu \mathrm{g} . / \mathrm{ml}$.

Assay of viral $R N A$. The nucleic acid preparations were diluted and adsorbed for $10 \mathrm{~min}$. at $18^{\circ}$ in different buffers and tested for infectivity by the plaque method. Dilution and adsorption in $2 \mathrm{M}-\mathrm{MgSO}_{4}$ according to Holland, Hoyer, McLaren \& Syverton (1960) gave 20 -fold higher titres than other methods tested ('Table 1). The nucleic acid infectivity was completely inactivated by treatment with ribonuclease which did not affect the titre of intact virus. The procedure adopted therefore included both dilution of the virus-RNA preparation and adsorption for $10 \mathrm{~min}$. at $18^{\circ}$ in $2 \mathrm{M}-\mathrm{MgSO}_{4}$. Cultures were subsequently washed twice with phosphate buffered saline (PBS) before application of the agar overlay.

Staining with fluorescent antibody. The indirect method was used. Coverslips with a uniform cell sheet were washed three times in PBS, fixed in acetone for $5 \mathrm{~min}$. and 
dried in air. Viral antiserum was subsequently applied for $30 \mathrm{~min}$. at room temperature, the slides washed three times in PBS and overlayed with goat antirabbit globulin conjugated with fluorescein isothiocyanate (Microbiological Associates, Bethesda, Maryland, U.S.A.). The sera were adsorbed with acetone powder from calf kidney.

Table 1. Infectivity of foot-and-mouth disease virus (FMDV) RNA under different experimental conditions

\begin{tabular}{|c|c|c|}
\hline \multirow[b]{2}{*}{ Diluent and adsorption medium } & \multicolumn{2}{|c|}{ p.f.u./ml. } \\
\hline & RNA & Intact virus \\
\hline $\begin{array}{l}2 \mathrm{M}-\mathrm{MgSO}_{4} \\
0 \cdot 9 \mathrm{M}-\mathrm{KCl} 0 \cdot 05 \mathrm{M} \text {-Tris (pH 8.0) } \\
\text { PBS }\end{array}$ & $\begin{array}{r}1.9 \times 10^{5} \\
9 \times 10^{3} \\
3.5 \times 10^{3}\end{array}$ & $\begin{array}{l}\text { n.d. } \\
\text { n.d. } \\
1 \cdot 3 \times 10^{10}\end{array}$ \\
\hline
\end{tabular}

n.d., Not done; PBS, phosphate buffered saline.

\section{RESULTS}

Resistance of persistently infected cultures to different viruses. The resistance of cells persistently infected with FMDV $\mathrm{O}_{2}$ to a challenge with related and unrelated viruses was investigated by following virus multiplication in persistently infected cultures of calf kidney, in such cultures cured by excess antibody, and in normal

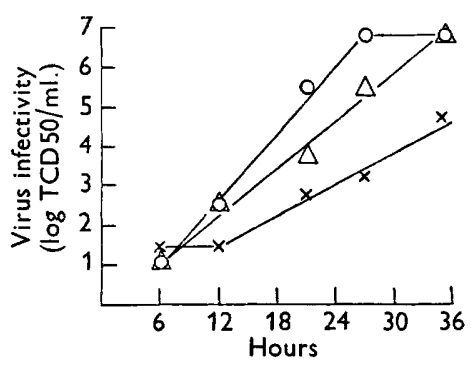

Fig. 1

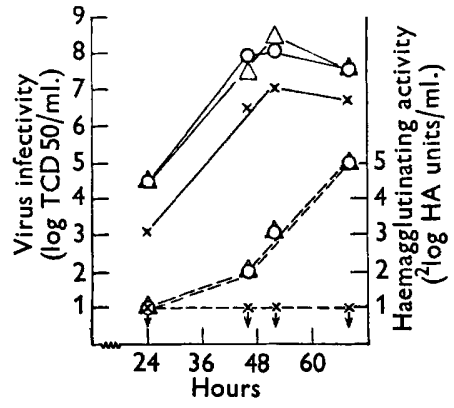

Fig. 2

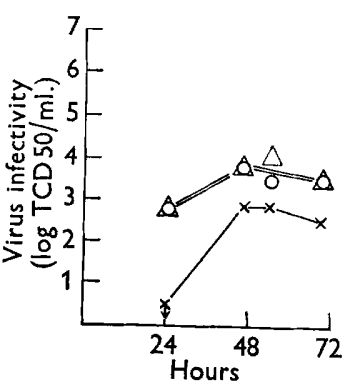

Fig. 3

Fig. 1. Growth curves for foot-and-mouth disease virus (FMDV) type $A_{5}$ in calf kidney cultures; $\times$, persistently infected with FMDV type $\mathrm{O}_{2} ; \triangle$, persistently infected with FMDV type $\mathrm{O}_{2}$ and subsequently cured with excess anti- $\mathrm{O}_{2}$ antibody; $O$, normal cultures.

Fig. 2. Growth curves for parainfluenza type 3 virus in calf kidney cultures; $\times$, persistently infected with foot-and-mouth disease virus (FMDV) type $\mathrm{O}_{2} ; \triangle$, persistently infected with FMDV type $\mathrm{O}_{2}$ and subsequently cured with excess anti- $\mathrm{O}_{2}$ antibody; $\bigcirc$, normal cultures. - , Virus infectivity; - -, haemagglutinating activity.

Fig. 3. Growth curves for pseudo-rabies virus in calf kidney cultures $x$, persistently infected with foot-and-mouth disease virus (FMDV) type $\mathrm{O}_{2} ; \triangle$, persistently infected with FMDV type $\mathrm{O}_{2}$ and subsequently cured with excess anti- $\mathrm{O}_{2}$ antibody; $\mathrm{O}$, normal cultures.

cultures. These cultures were challenged with 100 TCD50 of FMDV $\mathbf{A}_{5}$, parainfluenza-3 virus (PI-3) and pseudo-rabies virus. After different periods of incubation at $37^{\circ}$ samples were removed from the supernatant fluid and assayed for infectivity. 
When PI-3 challenge was used titres of haemagglutinin were also determined. Multiplication of FMDV $\mathbf{A}_{5}$ was suppressed in persistently infected cultures. The multiplication in cured cultures was only slightly inhibited compared with the controls (Fig. 1). Inhibition of multiplication of PI-3 and pseudo-rabies viruses was also evident only in persistently infected cultures and not in cured cultures (Figs. 2 and 3).

Cytopathic effect in persistently infected cultures challenged with different viruses. The cytopathic effect of a virus challenge on persistently infected, cured and normal calf cultures was followed in cultures infected with 100 TCD 50 of pseudo-rabies virus, FMDV $\mathbf{A}_{5}$, and RNA from the latter virus. Four plates were infected in each group. The cytopathic effect was graded from $0-4$. Cured and normal cultures were completely degenerated 2 or 3 days after infection, irrespective of the type of inoculum used for superinfection; the persistently infected cells scored between only $0 \cdot 5-1 \cdot 5$ on day 4 after infection (Table 2 ).

Table 2. Cytopathic effect of different challenge viruses on persistently infected foot-and-mouth disease virus (FMDV) cultures

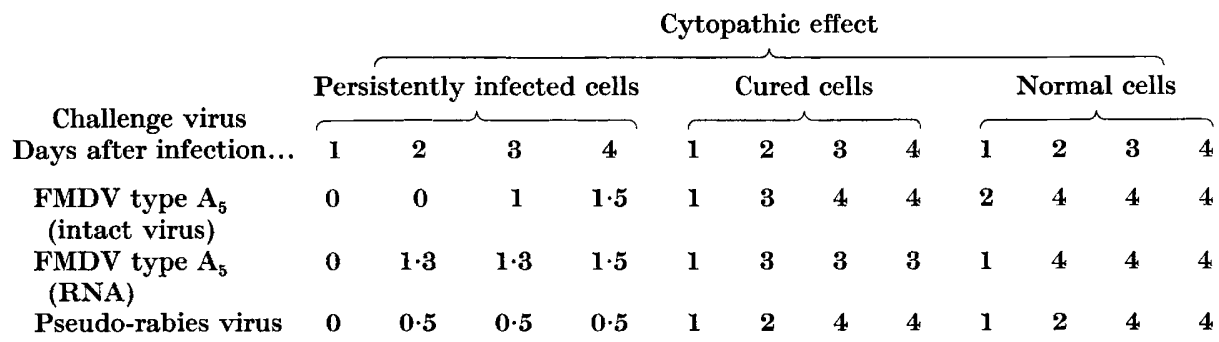

Cytopathic effect was graded from 0-4. The figures represent the mean for 3 cultures. The viruses were inoculated at day 0 in amounts of 100 TCD 50 per culture.

Table 3. Percentage fluorescent cells in normal calf kidney cultures at different multiplicities and in persistently infected cultures

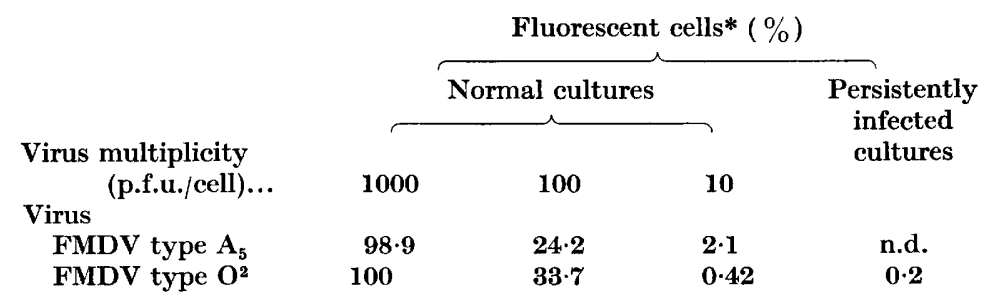

* Mean of 1000 counted cells from 4 slides; n.d., not done.

Staining of persistently infected cells with fuorescent antibodies. Calf kidney cultures persistently infected with $\mathrm{FMDV} \mathrm{O}_{2}$ synthesize virus in cycles. The titres in these cultures are 100- to 1000-fold lower than those in normal cultures. The viral yield implies either infection of one of 200-600 cells and a normal yield from this cell or else suppressed virus multiplication in all cells (Dinter et al. 1959). To differentiate between these two alternatives, cultures persistently infected with FMDV type $\mathrm{O}_{2}$ on coverslips were stained with fluorescent antibodies. As controls, 
normal calf kidney cultures on coverslips were exposed to FMDV $\mathrm{A}_{5}$ or FMDV $\mathrm{O}_{2}$ at different multiplicities for $30 \mathrm{~min}$. at $37^{\circ}$. Six hr. after infection the cultures were fixed and stained with fluorescent antibody. Cells exhibiting fluorescence in persistently infected cultures show the same intensity of fluorescence as normal cells infected with $\mathrm{FMDV} \mathrm{O}$ (Pl. 1). On the average one in 500 cells contains viral antigen in persistently infected cultures. Depending upon the multiplicity of infection, normal calf kidney cultures contain viral antigen in one in 50-200 cells at multiplicities of 10 and in every cell at multiplicities of 1000 (Table 3). The results suggest that the resistance of persistently infected cells to a challenge virus might be ascribed to a non-viral factor protecting the majority of the cells.

Attachment of challenge virus to persistently infected cultures. Persistently infected cultures and normal cultures were washed twice with PBS and inoculated with 300500 p.f.u. of FMDV $A_{5}$ in $0.2 \mathrm{ml}$. At intervals, $0.02 \mathrm{ml}$. was removed from each culture in the two groups, diluted tenfold in PBS and assayed for remaining infectivity on normal calf kidney cultures. The rate of attachment of FMDV $\mathbf{A}_{5}$ was the same in persistently infected and normal cultures (Fig. 4), indicating that blockage of attachment sites was not a major factor in maintenance of the persistent infection.

Challenge with viral $R N A$ in persistently infected and interferon treated cells. The experiments reported above suggested that a step in virus multiplication beyond attachment was blocked in the majority of the persistently infected cells. This block interfered alike with the synthesis of related and unrelated viruses. A similar effect has been ascribed to interferon which also inhibits virus multiplication when viral RNA is used as inoculum (Ho, 1961). To investigate this aspect properly, however, a cell system must be used which does not propagate the intact virus particle but gives only a single cycle of replication in response to the introduced RNA. Therefore calf kidney cultures, both persistently infected with $\mathrm{FMDV} \mathrm{O}_{2}$ and normal, were infected with 100 p.f.u. of RNA from poliovirus type 1 or FMDV $A_{5}$. At

Table 4. Yield of poliovirus type 1 in persistently infected calf kidney cultures of different ages with viral $R N A$ as inoculum

$\begin{array}{cc}\begin{array}{c}\text { Days after } \\ \text { induction of } \\ \text { persistence }\end{array} & \begin{array}{c}\text { Yield in p.f.u. } / \mathrm{ml} . \\ \text { at } 18 \mathrm{hr} . \text { of } \\ \text { incubation } \\ \text { (\% of control) }\end{array} \\ 2 & <0.5 \\ 7 & <0.5 \\ 11 & 4.0 \\ 14 & 10.0\end{array}$

intervals the cultures were frozen and thawed and the total yield of intact virus assayed in normal monkey and calf kidney cultures respectively. To study the role of interferon in maintenance of the carrier state, these experiments were also performed with persistently infected cultures of different ages. Intact poliovirus type 1 does not normally multiply in calf kidney cultures (McLaren, Holland \& Syverton, 1959). The yield of poliovirus type 1 in persistently infected cultures when viral RNA was used as inoculum was much decreased regardless of whether persistence had been established 2 or 14 days earlier (Table 4). The multiplication of FMDV 
$\mathbf{A}_{\mathbf{5}}$ in persistently infected cells was also inhibited when viral RNA was used as inoculum (Fig. 5). This latter finding alone does not permit the conclusion that in persistently infected cells, virus multiplication is blocked beyond penetration, since viral synthesis induced by intact FMDV $\mathbf{A}_{5}$ particles formed in the first cycle may be inhibited. With regard to the results with poliovirus, which cannot use calf kidney cells as a natural host, it is likely, however, that in both cases viral synthesis is blocked intracellularly.

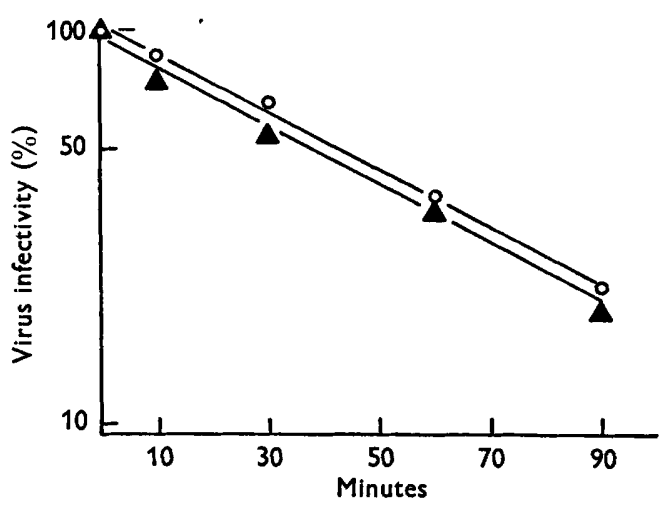

Fig. 4

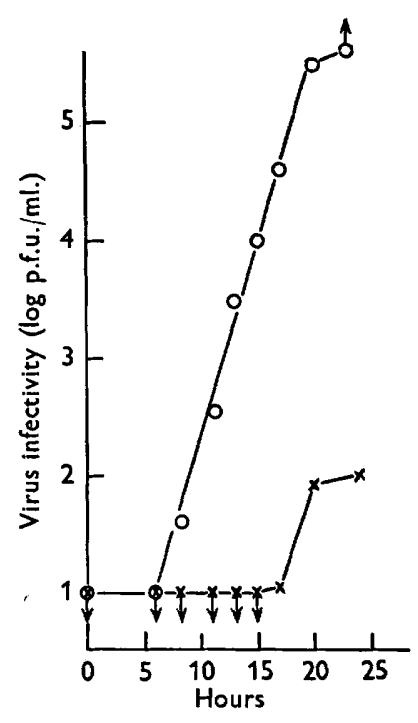

Fig. 5

Fig. 4. Attachment of foot-and-mouth disease virus (FMDV) $A_{5}$ to calf kidney cultures persistently infected with FMDV $\mathrm{O}_{2}(\mathrm{O})$ and to normal cultures (A). Virus infectivity is expressed as the \% p.f.u. remaining in the supernatant fluid after different periods of adsorption.

Fig. 5. Reproduction of foot-and-mouth disease virus (FMDV) in calf kidney cultures persistently infected with FMDV type $\mathrm{O}_{2}(\times)$ and in normal cultures $(O)$ after inoculation with RNA of FMDV type $A_{5}$.

The suppressed multiplication of challenge virus in persistently infected cultures was compared with the inhibition of viral synthesis by interferon in normal cultures. Calf and monkey kidney cultures were treated with interferon for $\mathbf{2 4} \mathrm{hr}$. and subsequently inoculated with 100 TCD 50 RNA from poliovirus type 1 and FMDV $A_{5}$. The preparation of interferon was described by Dinter \& Philipson (1962). After incubation for $18 \mathrm{hr}$. at $37^{\circ}$, control and interferon-treated cultures were frozen at $-60^{\circ}$, thawed and subsequently assayed for infectivity of intact virus in normal monkey and calf kidney cultures, respectively. The yield of the two viruses was suppressed in interferon-treated cells when viral RNA was used as inoculum. This effect was observed both in the natural host cells, monkey kidney for poliovirus, and in the calf kidney cells insusceptible to this virus (Table 5). Intact FMDV $\mathbf{A}_{5}$ however, multiplied in both calf and monkey kidney cultures.

Correlation between production of interferon and initiation of persistent infection. Persistently infected cultures were produced in tubes as described under methods. 


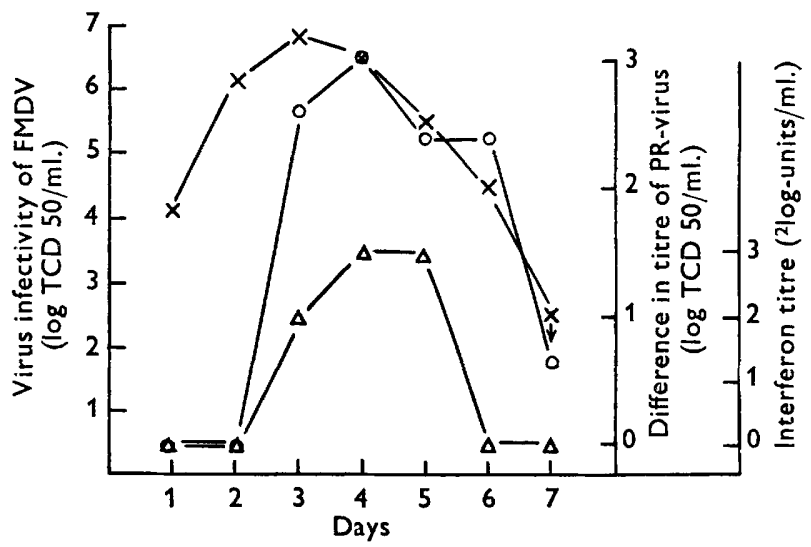

Fig. 6. Correlation between formation of infectious virus and the production of interferon in calf kidney cultures persistently infected with foot-and-mouth disease virus (FMDV). $\times$, Virus titre of FMDV type $\mathrm{O}_{2}$ in the medium; $O$, difference in titre of pseudo-rabies virus in normal cultures and in persistently infected cultures; $\triangle$, interferon titre of medium according to methods.

Table 5. Yield of foot-and-mouth disease virus (FMDV) type $A_{5}$ and poliovirus type 1 in interferon-treated calf and monkey kidney cultures with viral RNA as inoculum

Challenge RNA

100 p.f.u./culture

FMDV type $\mathbf{A}_{5}$ Polio type 1

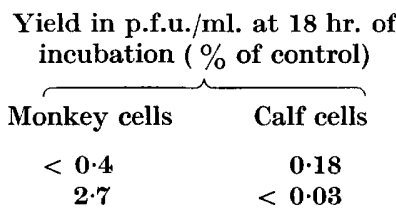

Yield in p.f.u. $/ \mathrm{ml}$. at $18 \mathrm{hr}$. of

$\begin{array}{cc}\text { Monkey cells } & \text { Calf cells } \\ <\begin{array}{c}\mathbf{0} \cdot 4 \\ \mathbf{2 . 7}\end{array} & \begin{array}{c}\mathbf{0 . 1 8} \\ \text { incubation }\end{array}\end{array}$

At daily intervals, the medium of 5 tubes was removed and pooled. The infectivity of $\mathrm{FMDV} \mathrm{O}_{2}$ was assayed and subsequently the interferon titre was determined in these pools after inactivating the virus by adjustment to $\mathrm{pH} 2.5$ with citrate buffer and back to $\mathrm{pH} 7$ with $0 \cdot 1 \mathrm{M}-\mathrm{NaOH}$. At daily intervals pseudo-rabies virus was also titrated in persistently infected and in control tube cultures. The difference in titres between these two titrations was considered an estimate of the resistance of the persistently infected cultures to the challenge virus. There was a rise in FMDV $\mathrm{O}_{2}$ titre with a maximum 3 days after the antiserum was removed from the persistently infected cultures. Interferon production and resistance to challenge virus reached a maximum at the 4th day after induction of persistence. The resistance to challenge virus was correlated in time with the interferon production in these cultures (Fig. 6). In this experiment the persistent infection was cured spontaneously at 10 days after induction; in other experiments, however, in which the persistent infection lasted for longer periods, the interferon titres were too low to be demonstrated 10-15 days after induction.

\section{DISCUSSION}

The studies presented demonstrate a correlation between interferon production and persistence of $\mathrm{FMDV} \mathrm{O}_{2}$ in calf kidney cultures during the early stages of the persistent infection. In persistently infected cells kept for 20-40 days, the presence 
of interferon could not be correlated with the resistance of these cells to challenge with another virus. Several theories can be put forward to explain this phenomenon. First, the interferon present might be bound intracellularly and more cells might be needed to demonstrate the presence of interferon. This is the case with MCN cultures persistently infected with myxoviruses (Henle et al. 1959). Secondly the interferon, initially present in the majority of the cells, might induce an alteration of the cells as reported by Gresser (1961). Evidence in favour of this theory has been obtained since the persistently infected cells show differences in morphology and nuclear size compared with controls (unpublished). Finally, since a heterogeneous cellular population was used, a selection of resistant cells might occur with gradual loss of cells susceptible to virus infection. This could also tally with the observed difference in cellular morphology of persistently infected cells. In a previous communication (Dinter \& Philipson, 1962) the possibility was discussed that the resistance to challenge virus could be due to a block of receptor sites on the cells by inactive virus. Such cells would produce virus normally if infectious RNA was used as inoculum as demonstrated by Crowell \& Syverton (1961). The present investigation demonstrates that the virus synthesis is inhibited when infectious RNA is used for challenge and that attachment of the challenge virus to the persistently infected cells is unaffected. All this favours the hypothesis that virus synthesis is blocked intracellularly.

This investigation was supported in part by a grant ( $\mathrm{E} 4193$ ) from the National Institutes of Health, U.S.A.

\section{REFERENCES}

Baron, S. \& ISAACS, A. (1961). Interferon and natural recovery from viral diseases. New Scientist 11, 81.

Chany, C. (1961). An interferon-like inhibitor of viral multiplication from malignant cells (the viral autoinhibition phenomenon). Virology, 13, 485.

Crowell, R. L. \& Syverton, J. T. (1961). The mammalian cell-virus relationship. IV. Sustained infection of HeLa cells by coxsackie B3 virus and effect on superinfection. J. exp. Med. 113, 419.

Dinter, Z. \& Philipson, L. (1962). An interferon produced by foot-and-mouth-disease virus (FMDV) in calf kidney cells. Proc. Soc. exp. Biol., N.Y. 109. 893.

Dinter, Z., Philipson, L. \& Wesslén, T. (1959). Properties of foot-and mouth disease virus in tissue culture. II. Persistent infection induced by temporary exposure of the cultures to antibodies. Arch. ges. Virusforsch. 9, 582.

Gierer, A. \& Schramm, G. (1956). Die Infektiösität der Nukleinsäure aus Tabakmosaikvirus. Z. Naturf. $11 b, 138$.

Glasgow, L. A. \& Habel, K. (1962). The role of interferon in vaccinia virus infection of mouse embryo tissue culture. J. exp. Med. 115, 503.

Gresser, I. (1961). Metamorphosis of human amnion cells induced by preparations of interferon. Proc. nat. Acad. Sci., Wash. 47, 1817.

Henle, W., Henle, G., Deinhardt, F. \& Bergs, V. V. (1959). Studies on persistent infections of tissue cultures. IV. Evidence for the production of an interferon in MCN cells by myxoviruses. J. exp. Med. 110, 525 .

Ho, M. (1961). Inhibition of the infectivity of poliovirus ribonucleic acid by an interferon. Proc. Soc. exp. Biol., N.Y. 107, 639.

Ho, M. \& ENDERs, J. F. (1959). Further studies on an inhibitor of viral activity appearing in infected cell cultures and its role in chronic viral infections. Virology, 9, 446.

Holland, J. J., Hoyer, B. H., McLaren, L. C. \& Syverton, J. T. (1960). Enteroviral ribonucleic acid. I. Recovery from virus and assimilation by cells. J. exp. Med. 112, 821. 



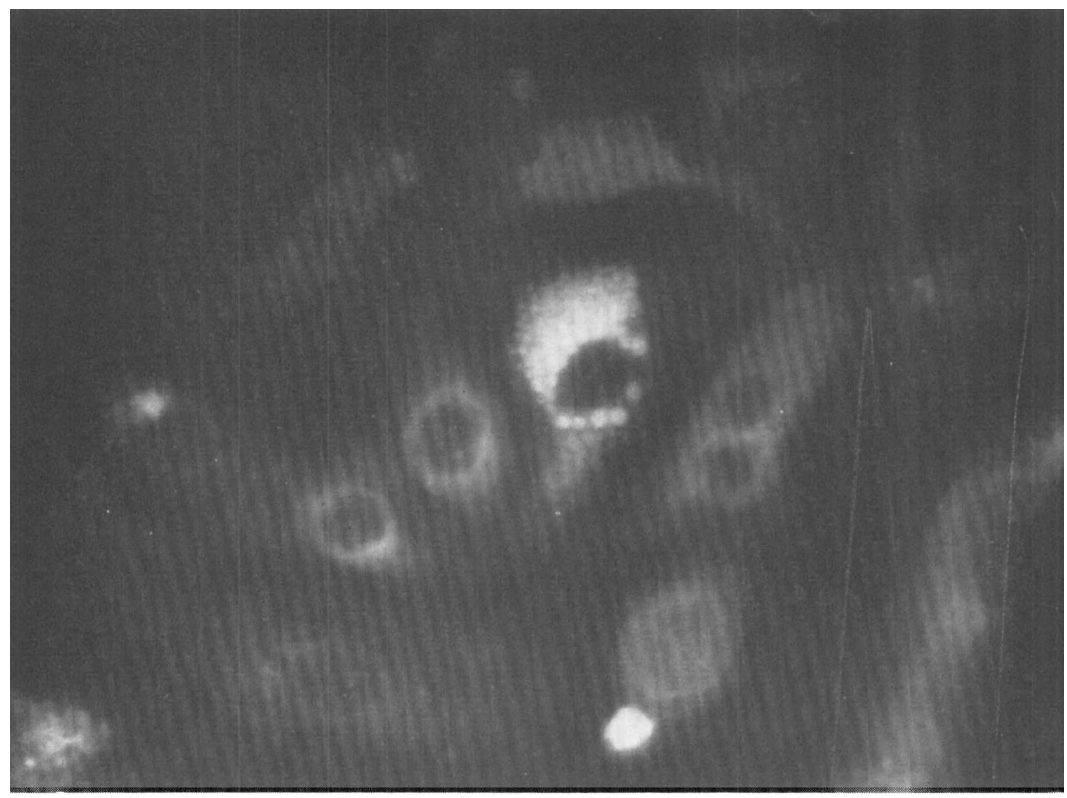

(a)

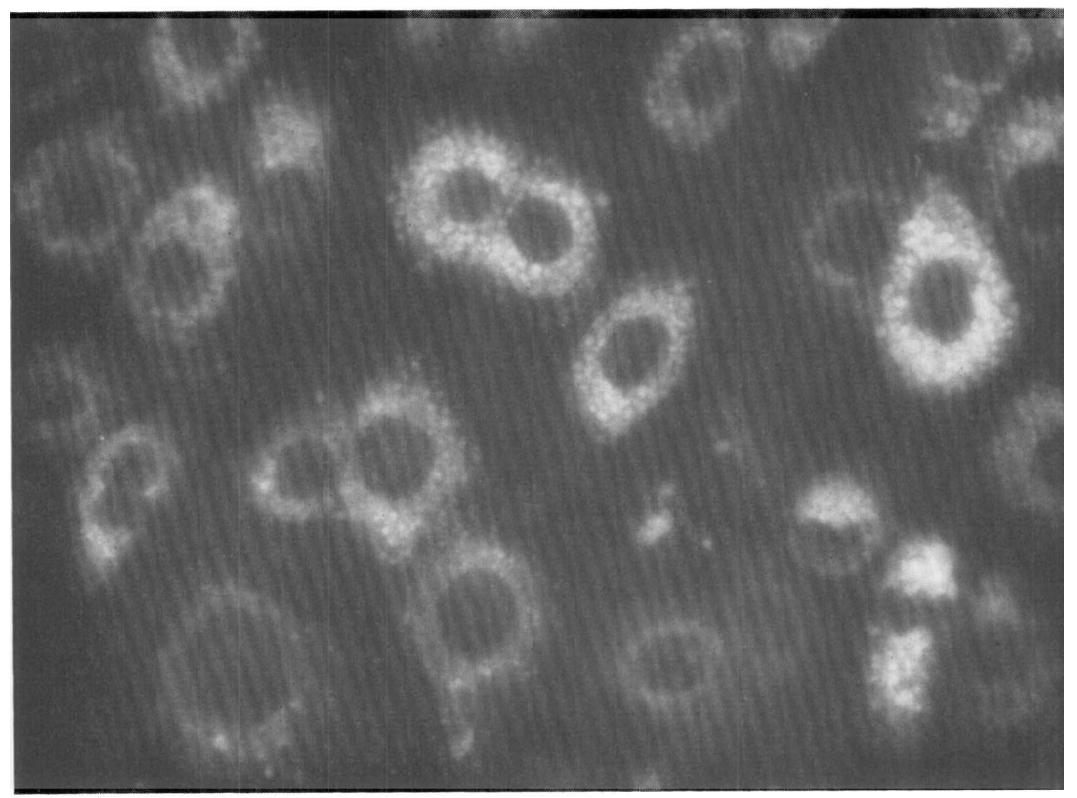

(b)

L. PHILIPSON AND Z. DINTER

(Facing p. 285) 
Holland, J. J., Mclaren, L. C. \& Syverton, J. T. (1959). Mammalian cell-virus relationship. III. Poliovirus production by non-primate cells exposed to poliovirus ribonucleic acid. Proc. Soc. exp. Biol., N.Y. 100, 843.

Isaacs, A. (1961). Nature and function of interferon. In Perspectives in Virology, 2, 117. Minneapolis: Burgess Publishing Co.

McLaren, L. C., Holland, J. J. \& Syverton, J. T. (1959). The mammalian cell-virus relationship. I. Attachment of poliovirus to cultivated cells of primate and nonprimate origin. J. exp. Med. 109, 475.

Philipson, L., Albertsson, P. Å. \& Frick, G. (1960). The purification and concentration of viruses by aqueous polymer phase systems. Virology, 11, 553.

\section{EXPLANATION OF PLATE}

Immunofluorescence of cells persistently infected with foot-and-mouth disease virus (FMDV) type $\mathrm{O}_{2}$; magnification $\times 800(a)$. Immunofluorescence of normal calf kidney cells infected with FMDV type $\mathrm{O}_{2}$ at a multiplicity of 50 at $6 \mathrm{hr}$. after infection; magnification $\times 800(b)$. 